\title{
Silencios de las mujeres docentes ${ }^{1}$
}

\author{
Yolima lezcano Pajón², Diva López Daza33, Luz Dey Reyes Campo4, \\ Ángela María Rodríguez Caicedo ${ }^{5}$, Miguel Alberto González González ${ }^{6}$
}

\begin{abstract}
Resumen
El lenguaje verbal es el principal medio por el cual los seres humanos establecemos nuestra realidad interna -pensamientos y sentimientos-, asimismo, es el vínculo primordial que tenemos para comunicarnos con el otro y su contexto. Pero ¿Qué podemos decir de lo no manifiesto? del "Silencio", implícito en actitudes, comportamientos o lenguajes sin voz que han estado callados y ocultos en las mujeres docentes. Estos silencios en algunas situaciones nos han llevado a preguntarnos ¿Por qué callamos? ¿A quién le sirve nuestro silencio? ¿Cuáles son las didácticas del silencio? ¿Qué nos puede estar silenciando? ¿Qué es lo no dicho de lo dicho? De ahí, que lo que implica el silencio puede verse normal o aceptado si se trata de una situación sin importancia; pero no sucede lo mismo si ese silencio conlleva a grandes implicaciones de lo que se calla, al entrar en juego las leyes, las políticas, las culturas, las religiones, las éticas y las morales.

Por las características de la investigación, ésta se inscribe en el enfoque cualitativo, dentro del método hermenéutico, el cual posibilita encerrar la realidad contextual propia y cercana a las necesidades de las autoras como grupo muestra de estudio. Las didactobiografías de las docentes fueron el insumo para identificar los silencios e implicaciones en el ejercicio académico como lenguajes del poder, que afectan los procesos internos y externos de sus vidas y, por consiguiente, los procesos formativos de enseñanza y aprendizaje de los estudiantes. También, tenemos la intención de abrir
\end{abstract}

1 Recibido: 29 de septiembre de 2013. Aceptado: 11 de mayo de 2014.

2 Yolima Lezcano Pajón. Profesional en desarrollo familiar Universidad Luis Amigó-Colombia. Especialista en intervención en violencia intrafamiliar Universidad Ramón Llull. Docente Uniminuto seccional Bello Colombia. Magister en Educación Desde la Diversidad en la Universidad de Manizales, Colombia. Correo electrónico: yolezpa43@une.net.co

3 Diva López Daza. Licenciada en Educación Básica con Énfasis en Ciencias Naturales y Educación Ambiental, Universidad del Cauca- Popayán-Colombia. Docente Institución Educativa Francisco Antonio de Ulloa de Popayán-Colombia. Magister en Educación Desde la Diversidad en la Universidad de Manizales, Colombia. Correo electrónico: divanalop@gmail.com

4 Luz Dey Reyes Campo. Licenciada en Educación Básica con énfasis en Educación Artística, Universidad del Cauca- Popayán-Colombia. Coordinadora pedagógica programa CDI modalidad familiar, ICBF; estrategia de cero a siempre. Magister en Educación Desde la Diversidad en la Universidad de Manizales, Colombia. Correo electrónico: luzsam23@hotmail.es

5 Ángela María Rodríguez Caicedo. Licenciada en Educación preescolar Universidad Autónoma del Cauca- Popayán-Colombia. Docente institución educativa Santa Rosa de Popayán-Colombia. Magister en Educación Desde la Diversidad en la Universidad de Manizales, Colombia. Correo electrónico: angelitarodriguez2@hotmail.com

6 Miguel Alberto González González. Director de la investigación: Lenguajes del poder ¿Lenguajes que nos piensan?, asesor y director de la tesis de maestría y del presente artículo devenido de la investigación. PhD en Conocimiento y Cultura en América Latina -IPECAL-México; PhD en Ciencias de la Educación Universidad Tecnológica de Pereira. Docente e Integrante equipo investigativo, Universidad de Manizales. Correo electrónico: mgcaronte@me.com 
camino a nuevas investigaciones que puedan surgir interesadas en indagar los silencios del poder, para dar voz a los silencios de las injusticias, las violencias, las guerras, las desigualdades, las discriminaciones y la impunidad. Sistemas de control disciplinario que operan en nuestra sociedad y gobiernan nuestra mente y cuerpo debilitando las promesas de libertad y emancipación.

Palabras clave: silencios, docentes, educación, lenguajes del poder, sistemas disciplinarios.

\section{Abstract \\ Silences of women teachers}

Verbal language is the main means by which human beings establish our inner reality -thoughts and feelings- It is the link we use to communicate with others and their context. But what can we say of the unmanifest? "Silence", implicit attitudes, behavior or language without voice has been silent and hidden in women teachers. These silences in some situations have leaded us to ask ¿Why silent? ¿Who serves our silences? ¿What are the didactics of silence? ¿What we can be silencing? What is the unsaid of the above? Thus, implied silence can accepted if it is happening in a not really important situation; but it is not the same when that silence leads to other major situations of what is silent, when the laws, politics, cultures, religions, ethics and morals to come into play.

For the characteristics of research, this is enroll in qualitative approach; within the hermeneutic method, which enables the contextual reality itself which is a close situation of the researchers as sample of the study. The didactobiografías of teachers were the essential input to identify the silences and implications in the academic exercise as languages of power affecting internal and external processes of their lives and therefore the teaching processes, learning and training of students. The didacto-biographies of the teachers were the input to identify the silences and their implications in academic exercises as languages of power affecting internal and external processes of their lives, therefore the teaching and learning processes of students. We also intend to open way to new investigations that may emerge interested in inquire into the silences of power, to give voice to the silences of injustices, the violences, wars, inequality, discriminations and impunity. The disciplinary control systems operate in our society and govern our minds and body weakening the promises of liberty and emancipation.

Keywords: silences, teachers, education, languages of power, disciplinary systems.

\section{Lo que nos convoca}

El presente artículo de investigación se vincula a la línea de investigación Lenguajes del Poder, dentro del macroproyecto "Lenguajes del poder. Lenguajes que nos piensan"; liderado por Miguel Alberto González González, investigador principal de la Universidad de Manizales, departamento de Caldas, Colombia. La particularidad de su estudio se adentra en los diferentes lenguajes que se mani- 
fiestan desde la perspectiva del poder y como éstos marcan de forma relevante el desarrollo y comportamiento del sujeto en la sociedad. La investigación se llevó a cabo entre marzo de 2012 y junio de 2013, participando las autoras como coinvestigadoras ${ }^{7}$ del estudio, a partir de la narración y análisis de sus propias didactobiografías concibiéndolas como "historia que se objetiva en una narración que da cuenta del desafío de leer y sistematizar el conocimiento de la realidad, a partir del análisis del presente en perspectiva histórica" (Quintar, 2013, p. 13).

El foco de estudio se centró en los silencios de género ${ }^{8}$, refiriéndonos en este caso a las mujeres docentes, su realidad, su ejercicio académico y su contexto social, cultural, afectivo, político, religioso y familiar. La búsqueda enfatizó en la identificación de los silencios e implicaciones en el ejercicio académico manifestadas en los lenguajes del poder.

Lo expuesto, se desarrolló en los siguientes momentos investigativos. En el primer momento, presentamos la justificación como necesidad de ahondar en los escenarios del silencio, sus razones, sus didácticas y lo que deviene detrás de una sociedad que calla, que aísla la voz, que esclaviza los sentidos, el conocimiento y la palabra; además, contempla los antecedentes que exponen que los silencios no son una casualidad propia de los estados de prudencia, intimidad o privacidad que rodea al ser, por el contrario, vienen configurados por los sistemas e instituciones.

7 Las docentes investigadoras son oriundas, una del departamento de Antioquia, otra, de Nariño, y dos del departamento de Cauca, siendo el punto de encuentro la ciudad de Popayán.

8 "Silencios de género" alude al concepto de género que expresa la construcción social de la feminidad, que Simone de Beauvoir plantea en su obra El segundo sexo para reivindicar sobre la condición de mujer. Carnero, Silvia. $(2005,5)$. La condición femenina desde el pensamiento de Simone de Beauvoir. Revista A PARTE REÍ 40, Julio de 2005.
El segundo momento, acoge el problema de investigación, el cual gira alrededor de los silencios de las mujeres docentes; presentamos, los objetivos movilizadores del proceso investigativo; describimos el referente teórico que fundamentó la búsqueda de los silencios subyacentes en los sistemas, instituciones y lenguajes del poder; y puntualizamos en el diseño metodológico, detallando la población muestra de estudio para llegar a resultados peculiares y significantes.

En el tercer momento, exponemos los hallazgos producto del diálogo entre los objetivos de la investigación, las didactobiografías de las mujeres docentes y la construcción de sentido del proceso mismo desarrollado; conferimos unas conclusiones que emergen de la pregunta investigativa, y de los aportes que los teóricos nos ofrecieron como puerta abierta para tensionar el conocimiento, los medios y las prácticas que encierran silencios como lenguajes del poder. Por último, se finaliza con las recomendaciones que tienden a movilizar el pensamiento y la palabra como factores que liberan los silencios de las imposiciones del poder.

\section{La excusa}

"Silencios de las mujeres docentes" es un estudio que se realizó en el campo de la educación. Esta investigación descriptiva se realizó a partir de las didactobiografías así se identificaron los silencios y las implicaciones de esos silencios en el ejercicio académico comprendiendo la necesidad de ser sujetos activos en las problemáticas educativas como nos alerta González $(2009,16)$ al referir "leer la realidad a tiempo, no esconderse ante los problemas y, como en todos los períodos, no ser inferior al espíritu de la época..., exige un reconocimiento de las amenazas para perfilar desenlaces y tratar de vencer las dinámicas que lo limitan“. Es decir, se hace necesario retomar y reconocer la palabra no nombrada, lo no manifestado, 
lo callado, para proponer nuevos lenguajes que se entrelacen con las narrativas, el diálogo y la participación colectiva en procesos formativos que recuperen la memoria del pasado que nos signa y permita reconfigurar nuevas proyecciones de bien común.

\section{Huellas del silencio}

Los antecedentes consultados en sus planteamientos, distinguen los silencios como componentes inmersos en los lenguajes del poder, que pueden ser direccionados desde diferentes tácticas de dominio y control sobre los individuos.

Investigaciones correspondientes a la línea de investigación Lenguajes del poder; abordan el silencio en diferentes escenarios. Miguel González (2009), en su texto, "El lenguaje como generador de conflictos", refiere que las múltiples maneras en las que se adopta el proceso comunicativo pueden emerger en discusiones y aconseja guardar silencio, para evadir la trampa del lenguaje con encadenamiento de expresiones que conllevaría a un riesgo de violencia. El lenguaje como proceso comunicativo puede generar conflictos, y por consiguiente silencios según sean las situaciones sobre las que se establezca la comunicación. Margarita Álzate, Guzmán, Henríquez y Meléndez, en la investigación "Los olvidos de los docentes" (2011), manifiestan que el olvido es la salida a la visión pesimista de la profesión docente, que lleva a los docentes a guardar silencio y esconder sus propias experiencias, sus propias prácticas, generando muchas veces frustración de la labor, perdiendo la autonomía y llevándolos a convertirse en simples técnicos de la educación. Por su parte, Clara Collazos y Luisa González (2012), presentan su tesis "Los lenguajes del poder. Miedos de los docentes", exponiendo las afecciones que causan en los docentes temores y miedos, y la incidencia en el desarrollo de la calidad de la educación, donde el silencio y el poder no dejan de vislumbrarse como productores de dichas afecciones.

En relación a los lenguajes del poder, Garrido (2008), en "El valor del silencio en el proceso de mediación. Un medio para la paz", aborda el silencio con amplios fines hacia la conciliación, lo describe como una herramienta comunicacional, resaltando el gran valor de analizar y utilizar el silencio para la resolución de conflictos que se generan a raíz de las dificultades que se presentan en los procesos comunicativos y de mediación. Asimismo, Tobón (1987), en "Semiótica del Silencio", interviene comparando las instituciones educativas como prisiones donde el silencio lleva a la exclusión, la tiranía, la manipulación, el autoritarismo y a la disciplina que es impuesta de forma negativa coartando e imponiendo castigos como estrategias de enseñanza y aprehensión de la norma.

Desde otra posición, Von Der Walde (2001) consciente del poder del lenguaje como medio de comunicación y socialización para ofrecer el conocimiento y explicar la razón, en "Filosofía y silencio", al abordar planteamientos de Platón, estudió el silencio como medio reflexivo que lleva al análisis profundo de las cosas. Estrategia que permite la interiorización, la contemplación de las experiencias que nos constituyen y adquisición de la verdadera sabiduría.

\section{Problema de investigación y desafíos}

Siendo los silencios la temática sobre la que ambicionamos iniciar un proceso investigativo para conocer qué nos ofrecen como problemática real de la educación y de los lenguajes del poder, hemos delimitado la siguiente pregunta de investigación: ¿Cuáles son los silencios de las mujeres docentes y cuáles las implicaciones de esos silencios en su ejercicio académico? 
Nuestros desafíos son Como objetivo general de la investigación se planteó iidentificar los silencios de las mujeres docentes y las implicaciones de esos silencios en su ejercicio académico.

Pertinentemente, los objetivos específicos planteados fueron descubrir los silencios de las investigadoras en todo su contexto; interpretar los silencios hallados en las docentes investigadoras; reconocer qué silencios en las mujeres docentes son más frecuentes en el aula de clase; clasificar los silencios de las mujeres docentes e incidencia en el ejercicio académico y analizar que silencios se convierten en lenguajes de poder por parte de las mujeres docentes.

\section{Nuestra brújula}

El lenguaje es sin duda el medio de expresión inherente de los seres humanos. Los silencios yacerían entonces como una de las tantas consecuencias de censurar las necesidades de expresión presentes en las posibilidades del lenguaje. Relacionando así los silencios, como representación de poder y de los lenguajes del poder funcionando en los escenarios comunicativos, laborales, culturales, religiosos, políticos, sociales y de la educación.

Desde el estudio del poder, Foucault (1984, p. 141) en Vigilar y castigar, "el cuerpo humano entra en un mecanismo de poder que lo explora, lo desarticula y lo recompone", surge el "castigo disciplinario", donde el silencio es un mecanismo represivo. Al silenciar la palabra, se invisibilizan las injusticias, las violencias, las desigualdades y la vigilancia. Emergiendo en las sociedades la disciplina, el sometimiento y el orden, y, en la educación, instituciones disciplinarias que perpetuán estos subpoderes. A su vez, en la teoría La espiral del silencio, Noelle-Neumann $(1992,10)$ plantea, "el clima de opinión depende de quién hable y quién permanezca en silencio" así, la opinión pública es una forma de control social. Los individuos al tener miedo al aislamiento del entorno social se protegen en la pasividad del silencio, adaptando su comportamiento a lo establecido por la opinión mayoritaria o dominante.

En el interés por recurrir a la didactobiografía para identificar las implicaciones de los silencios en el ejercicio académico, nos dice Guarín $(2009,265)$ "La literaturización de la vida cotidiana en la didáctica formativa es lo que desencadena para ella el gran valor de las narrativas; esto es indispensable para un educador, para un formador". El escudriñar los silencios en aquellas épocas de sentido trascendentales que viene cargadas de hechos significantes que nos posiciona y constituyen como sujetos vitales, históricos y sociales.

Desde la óptica de Fromm, (1993, p. 20) en El miedo a la libertad, refiere que "el hombre moderno, libertado de los lazos de la sociedad pre-individualista —lazos que a la vez lo limitaban y le otorgaban seguridad-, no ha ganado la libertad en el sentido positivo de la realización de su ser individual, esto es, la expresión de su potencialidad intelectual, emocional y sensitiva" por tal, se aísla, se silencia y se somete a las formas de gobierno y estandarización de las actividades, de los comportamientos y de las acciones, para sentirse acogido por la sociedad.

La destacada pedagoga Gabriela Mistral, (1924) desde las condiciones de género como mujer, sus enseñanzas nos llevó a preguntarnos ¿Qué significado tiene en la vida de las mujeres el ser docentes? Movilizándonos a comprender que la práctica pedagógica debe aislarse de las normatividades del silencio establecidas como opciones de vida que coartan y debilitan las posibilidades de emancipación del ser. Invita a que alimentemos en las estudiantes y los estudiantes las capacidades de expresar su pensamiento, saberes, sentir y actuar en condiciones de igualdad y ambientes propicios de participación colectiva. 


\section{Nuestra ruta}

La investigación se direccionó desde el enfoque cualitativo, ajustando el análisis e interpretación de la información por medio del método hermenéutico. Pues, "la vida como realidad fundamental, compartida a través de las vivencias individuales, soporta el nexo que da unidad a la historia" (Gómez, S, f., p. 13, citando a Dilthey), y posibilita encerrar la realidad contextual propia a las autoras como grupo muestra de estudio y guiar la investigación en este caso a la identificación de los silencios y de las implicaciones de esos silencios en el ejercicio docente.

La información recolectada fue analizada por las propias docentes co-investigadoras a partir del diseño descriptivo e interpretativo. La solicitud de comparación fue realizada entre las mismas didactobiografías de las docentes teniendo en cuenta las diferencias de la realidad, experiencia contextual y regional por ser oriundas de los departamentos de Antioquia, Nariño y Cauca. Al identificar en los silencios los efectos que habían tenido en las vidas de las autoras, estos efectos se dedujeron como posibles implicaciones que se desencadenaban al callar frente a las normas, el disciplinamiento y las condiciones sociales, políticas, religiosas, familiares, educativas y culturales ya preestablecidas para vivir en sociedad. Otros aportes analizados que nutrieron los análisis se obtuvieron de puestas en escena a través de pantomima y obras artísticas (elaboración del cuerpo en yeso y pintura sobre lienzo) creadas por las co-investigadoras para dar cuenta del proceso que seguía la investigación.

La población y muestra que se seleccionó para este estudio es representativa de las mujeres docentes porque se tuvo en cuenta las didactobiografías de las cuatro docentes investigadoras. Una docente universitaria de Uniminuto seccional BeIlo- Antioquia, y tres docentes de básica primaria de las Instituciones Educativas: Francisco Antonio de Ulloa, Sede: Los
Sauces, y, de la Institución Educativa Santa Rosa, sede principal, Popayán-Cauca.

\section{Hallazgos}

La información analizada e interpretada, primero presenta los silencios unánimes y los silencios distantes o peculiares a cada una de las docentes, y por último expone las categorías representativas al estudio de los silencios encontrados.

\section{Silencios unísonos}

Al analizar las historias de vida de las co-investigadoras y confrontar el dialogo con los teóricos, encontramos que hay prácticas del silencio en el amor, la religión, la educación y en la familia que nos marcaron de forma similar según el contexto propio a cada una de las docentes.

Son muchos los contextos donde el silencio ha coexistido en el ser humano, dejando huellas imborrables que se perpetúan con la vida. Gabriela Mistral, recrea el silencio en las relaciones afectivas. En nuestras sociedades las mujeres han sido condicionadas para callar y no expresar sus ambiciones o sueños propios del proyecto de vida, atribuyendo a ese silencio un don especial con el imaginario de que se encarga de conservar la vida de pareja, el hogar y fomentar la sana formación de los hijos. Lezcano (2012) nos relata, "15 años dedicados a un matrimonio ficticio, planeado no amado, hecho por calmar las angustias de la familia, por la idea errada, de dar un padre a un hijo solo". Estas situaciones han conllevado a que la mujer deje de lado sus ambiciones, sus metas, sus sueños y deseos de realización personal y profesional.

Entonces, las mujeres hemos sido educadas de una forma particular, especialmente desde los estamentos de la religión. Es por esta razón que hemos callado las agresiones, la esclavitud, la ridiculización, la pérdida de oportunidades, el dolor, el ultraje, la minimización, las carencias, 
las ausencias. El recorrido a través de los análisis nos ofrecía otra apreciación aparte de que se corroboraba los silencios como mecanismo de subordinación también llegábamos a inferir que éstos desencadenaban sucesos de resistencia en razón que al callar ciertas situaciones se lograba en cierta manera evitar que algunas problemáticas se empeoren como por ejemplo querer proteger a una o varias personas, un ideal o la propia integridad. Estos hechos se evidenciaban en la realidad de las autoras, pues sus narraciones describían episodios en los que soportaban y aguantaban situaciones injustas o no deseadas por medio de sus silencios que vendrían a ser "elementos de resistencia que Foucault considera en su tratamiento de la dominación" (Ottonello, 2011, p. 22). Resistencia entendida como forma de luchar, de oponerse y autoafirmarse para no permitir volverse presas de la vulnerabilidad y la coacción.

En la educación, las autoras tienen y practican silencios en el aula, que inciden en los estudiantes y en su aprendizaje. Convergiendo en señalar los silencios que no son positivos, pues interfieren el quehacer y el fin educativo. López, (2012) "si había algo que nos permanecía constantemente taladrando hasta los tuétanos era la disciplina, el estar ordenados y en silencio, nos callaban en las formaciones, en el salón, en los pasillos y hasta en los descansos". Analizar dichos silencios favorecía buscar maneras de encauzarlos de tal forma que no sean factor de represión, sino que proporcionen beneficio y permitan redireccionar las prácticas formativas. Las docentes autoras se han encontrado en su función académica desde la expresión de sus propias motivaciones, preocupaciones y pasiones al ejercer la docencia. Al respecto, Simone de Beauvoir (1949) contextualiza su concepto sobre las mujeres docentes mirando su quehacer desde la filosofía, donde ciertas dinámicas -la exteriorización de los silencios- posibilitan que el trabajo como docentes sea gratificante y se convierta en una filosofía de vida que puede transmitirse a los estudiantes de cualquier nivel académico con el ánimo de transformar sus vidas y de iniciar procesos colectivos de retroalimentación que los converja en la búsqueda de un bien común.

\section{Silencios distantes}

En el proceso de la investigación, se encuentran con discrepancias en cuanto a protagonismos y responsabilidades. Cada uno de los sucesos presentados se tomaron como silencios que viven las y los educandos y educadores. En relación a nuestra posición como mujeres, Lagarde (1990, p. 2) reseña "las mujeres comparten como género la misma condición histórica y difieren en sus situaciones particulares, en sus modos de vida, sus concepciones del mundo, así como en los grados y niveles de la opresión". Es de esta manera que se ratifica, que las personas como seres pensantes, racionales y únicos, siempre van a tener diferencias que son silenciadas buscando la mejor manera de adaptarse a las situaciones o al medio.

Cabe resaltar que a veces por complacer a los demás o evitar discusiones, callamos nuestras inconformidades, pero también es cierto que a veces callamos por no tener las bases suficientes para hacer respetar nuestras posiciones, saberes, decisiones y dignidad. Es necesario reafirmar nuestra identidad, pues, "Mientras más se gana en experiencia vivida en el protagonismo, en la autonomía, en el poder como afirmación, mientras más se toma la vida en las manos, más se define cada mujer como sujeto de su propia vida" (Lagarde, 1990, p. 9).

A la vez, en las autoras, se evidencia que Lezcano (2011), Reyes (2011) y Rodríguez (2011) aún enmudecen sus voces para evitar los señalamientos de los otros, amordazando las voces de las inconformidades dentro del ejercicio, que observan como atropellos a los entes por "educar". Entonces, "nos agrada el otro 
cuando se parece a mí comportamiento, pero lo desconozco cuando no se aproxima a lo que pienso o deseo" (González, 2011, p. 2), razón por la cual, se convierten en sometedoras de otros silenciándolos o auto-silenciándose en sus deseos, necesidades o quizá por temor a perder el "status" ganado gracias a la ubicación laboral asegurada.

Uno de los mayores desencuentros de las autoras, radicaba precisamente en la diferencia de pensamientos, deseos y formas de hacer las cosas. El análisis exhaustivo de este desencuentro académico y humano retoma a Freud (1925), desde su concepto de deseo, el autor lo considera como un acto inconsciente de los seres humanos con el fin de obtener placer; aspiración que se diferencia de la necesidad, pues ésta se refiere a la supervivencia y adaptación. Foucault, en sus observaciones sobre el poder, establece que en una situación estratégica que busca tener tácticas dominadoras, el poder no sólo reprime sino que produce efectos de verdad, de saber, de conocimiento que propende por una lucha interminable de ser atendido, creído y valorado.

Entonces, se evidencia como los constructos mentales de las nuevas generaciones tienden a buscar esas formas de gobernar a los otros. Noelle-Neumann, (1995, p. 33) afirma, "nuestra naturaleza social nos hace temer la separación y el aislamiento de los demás y desear ser respetados y queridos por ellos", percibiéndose que quienes no tienen ese poder de gobernar por lo general callan las inconformidades, sus diferencias y las reprimen para evitar inconvenientes con sus pares o con quienes los rodean.

\section{Introspecciones de cuatro mujeres docentes}

Los espacios de reflexión alrededor de las didactobiografías para identificar los silencios de las mujeres docentes y las implicaciones de esos silencios en el ejercicio académico, permitieron develar situaciones que marcaron de manera significativa su personalidad y su quehacer en los contextos laborales y personales, $y$, delimitar las siguientes categorías emergentes del proceso investigativo.

\section{Poros amordazados}

Poros: en esta oportunidad para estudiar la categoría referente a la religión y moral, las investigadoras usaron el término poros para referirse a la característica de tener boca, de posibilidad de exteriorizar.

Amordazados: término usado para referirse a la forma de represión, de prohibición a hablar o exteriorizar una inconformidad.

Religión y moral: desde este ámbito las co-investigadoras han recibido una educación católica. Esta categoría infiere que la religión es la institución que más ha influido y censurado la posición del ser humano frente a su derecho de libertad $e$ igualdad.

En Colombia, la religión católica ha sido una tradición para la educación de las personas, influyendo en la familia, en la forma de vida, de educación y posición ante la sociedad. De ello que al establecerse como paradigma de organización en la estructura familiar y social, hubiese un marcado interés de los padres para que sus hijos recibieran una educación religiosa. Indica Rodríguez (2012) "desde muy pequeña mi madre hizo lo posible para que me pudieran recibir en una institución de carácter religioso", elección que era muy pertinente cuando de educar a los hijos e hijas se trataba, en especial a la mujer, pues las instituciones religiosas eran las ideales para moldearla en el rol servicial que se necesitaba. Efectos silentes que como mujeres e hijas se debía vivir como signo de obediencia y sumisión bajo un credo y condiciones instaurados por la religión.

Dar voz a los éstos silencios, permitió cuestionarnos sobre las imposiciones de poder que guarda la religión. Compren- 
diendo que la religión debe asumirse y entenderse como una forma de vida basada en la fe y la espiritualidad. Nietzsche, reseña cómo el hombre no puede ser inferior ni convertirse en objeto de la religión y su sistema de poder, manifestando que "las creencias funcionan como potencias, hasta el punto que se podría hablar de creencias-fuerza, de dispositivos irreales pero capaces de generar realidad, la misma realidad que se generaría si los dispositivos creenciales fuesen realidades" (Hernández, 2007, p. 5, citando a Nietzsche). Pues, es necesario que se reflexione frente a la religión, y, si ésta es aceptada, sea una decisión tomada de manera consciente e interiorizada, donde su fin principal debe encauzarse a dar cuenta de individuos sensibles en el respeto, la aceptación del otro y la hermandad.

Por tanto, analizar los silencios desde la negación de las posibilidades de exteriorizar los diferentes acontecimientos en los que como personas y sociedad estamos en igualdad de derechos, en la figura 1 se muestra como la religión y la moral ha tenido unas variaciones en la historia de las co-investigadoras en cuanto al valor que ha ido tomando la palabra, la participación y el reconocimiento en la medida que nuevas leyes y normas se han ido incorporando en la sociedad. En el aparte sobrevenido, encontramos como las situaciones a silenciar estaban fuertemente arraigadas al poder que representaba la tradición, el régimen, la $\mathrm{fe}$, el dominio, la represión, entre otros condicionamientos que establecían la subordinación. Seguido encontramos el aparte vigente, donde se establece un ligero cambio de los escenarios antes mencionados que con el pasar de los tiempos, los avances y las trasformaciones sociales se ha logrado un progreso positivo en cuanto a que la expresión de necesidades sea una alternativa de libertad, decisión, conciencia y participación.

Figura 1. Poros amordazados

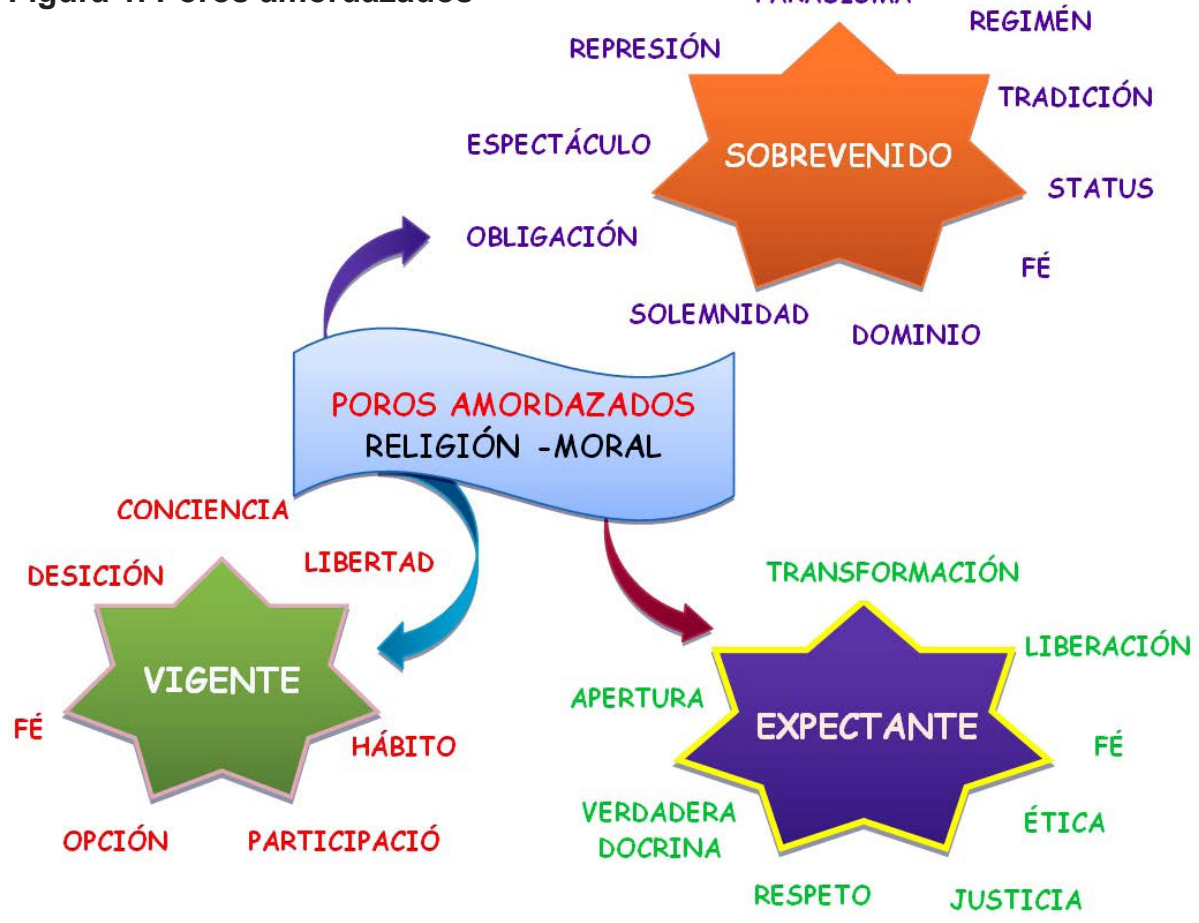


Y el último aparte como visión expectante de lo que debería representar la religión y la moral descartando métodos de silenciamiento y promoviendo una actitud de transformación, liberación, apertura, respeto y justicia.

\section{Silencios corrosivos}

Corrosivos: en esta categoría es necesario resaltar que la palabra corrosivos será usado por las investigadoras como una forma de identificar la herida que dejo en la esencia de nuestras vidas el silenciamiento de las manifestaciones afectivas.

Afectividad: La mujer ha sido formada desde la moral basada en la religión católica como lo mencionamos en la categoría anterior, así, en la medida que se expresaban los silencios se exteriorizaba los sentimientos que determinan las formas como habían emprendido sus diferentes relaciones afectivas.

Como mujeres, estos sentimientos si eran bien vistos culturalmente, en determinados casos podían ser expresados libremente o por el contrario sino eran aceptados, eran reprimidos por la condición de género como mujeres y posición que tenemos ante la sociedad. Los sentimientos de amor verdadero y sin condicionamientos eran desarraigados de la mujer pues su rol debía limitarse principalmente a los oficios de casa, de madre y compañera sexual. En esa desigualdad de necesidad afectiva entre hombres y mujeres, Lagarde (2008, p. 3) nos explica, "para los hombres el amor es poder en sí, una forma de incrementar megalomanías y narcisismos, así como de ejercer su dominio sobre las mujeres y sobre el mundo. Este amor contiene la desigualdad y la jerarquía como componentes sociales de género. Por ello, las parejas diseñadas para este amor son disparejas". En este sentido, unos silencios provenían de crianza que los padres implantaban en sus hijas, por temor, por apariencias o por conveniencias; otros como forma de sumisión para evitar decepciones y momentos desagradables a los padres, a las parejas o a los esposos.
El afecto es una necesidad primordial en el ser humano para su desarrollo; la afectividad desde los primeros años es la base de la confianza y la autoestima que la persona pueda llegar a tener en el futuro, con el deseo que pueda ser autónoma, libre y responsable frente a las diferentes situaciones que la sociedad le depara. Como lo plantea Fromm (2000, p. 35), "la persona madura se ha liberado de las figuras exteriores de la madre y el padre, y las ha erigido en su interior". Partiendo de este concepto las investigadoras han tomado la afectividad como un factor indispensable en la vida, ya que, en los roles que desempeñan como madres, esposas y docentes, este valor se ha visto tergiversado por las diferentes condiciones de crianza que recibieron, lo que llevó en cierta manera a que no se dé una autoafirmación como mujeres con igualdad de derechos, condiciones y oportunidades. Algunos ejemplos: noviazgos impuestos, noviazgos por temor a soledad o por carencia afectiva, nos acerca a entender la importancia de los sentimientos como factores vitales para la madurez e identidad de las personas. La cita a continuación nos da una referencia de las necesidades afectivas, "cuando Ilegué a pertenecer a la familia de mi esposo..., me encontré con el modelo de un padre cariñoso con sus hijos, me preguntaba ¿Por qué mi padre no fue o no es así conmigo? Siento tantos celos de no poder tener lo mismo, siento tanta rabia por tener un padre tan frio, siento angustia de saber que mi hermanita vive lo mismo y siente lo mismo, que así como yo busque ese calor de padre en otros hombres teniéndolos como pareja, tal vez, mi hermana puede estar haciendo lo mismo." Reyes (2012).

Determinadas situaciones vividas a raíz de los núcleos familiares y sus costumbres o resultado de problemáticas presentes en las familias disfuncionales, llevan a que se busque ansiosamente la afectividad y la aceptación del otro en cualquier momento cuando nos relacionamos y apreciamos 
Figura 2. Silencios corrosivos

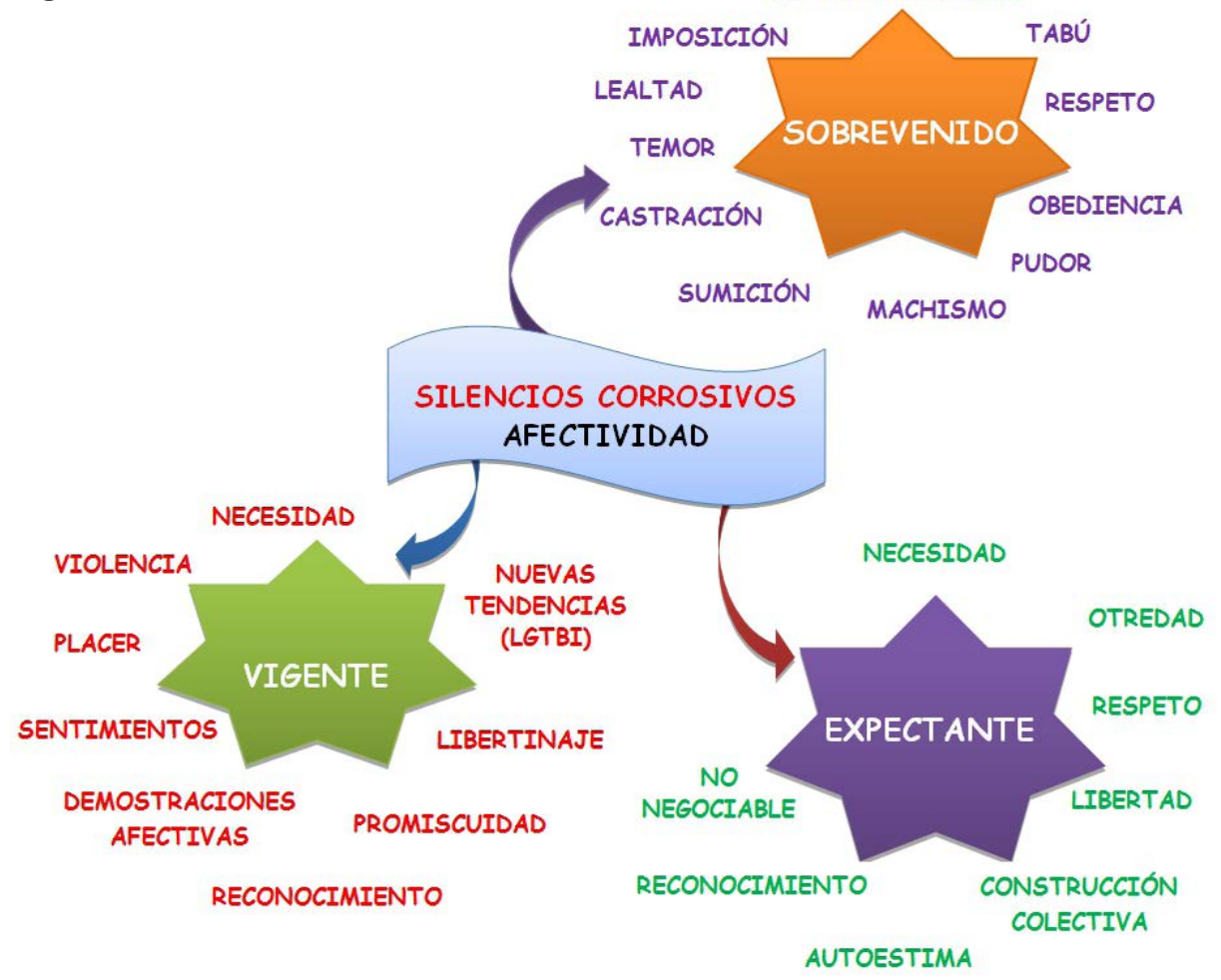

que otras personas pueden suplir esas carencias afectivas que no se lograron materializar dentro de la familia.

El afecto en muchas ocasiones no es considerado como componente significativo, vital para la seguridad, crecimiento del individuo y fortalecimiento de los lazos familiares independiente de cómo este constituido el hogar. La figura 2 nos muestra como la categoría de silencios corrosivos alude a aquellas situaciones afectivas que inicialmente en el aparte sobrevenido tenían que ver fuertemente con formas de imposición, tabú, temor, lealtad, castración, sumisión, machismo, entre otros factores que llevaban a que como mujeres estuviéramos en condiciones desfavorables de expresarnos abiertamente. Seguido en el aparte vigente inferíamos que actualmente se establecen situaciones polarizadas, por un lado encontramos como se ha logrado satisfacer en cierta medida las necesida-

des, sentimientos, reconocimiento y demostraciones afectivas, pero por otro lado ha emergido, incrementado o salido a la luz casos más incidentes de violencia, libertinaje, promiscuidad y nuevas tendencias (LGTBI) como desencadenamiento del condicionamiento de las verdaderas posibilidades de libre expresión. Por último, en lo expectante visionamos que se pueden movilizar factores que prevalezcan la afectividad como resultado del reconocimiento, la otredad, la autoestima, el respeto y la construcción colectiva para todos y todas en escenarios reales y posibles de igualdad.

\section{Silencios efervescentes}

Efervescentes: Para las investigadoras, palabra usada como forma de entender que se acaba la calma y en forma de burbujas se agita, sube y rebosa la superficie.

Laboral: Las oportunidades de ingresar al campo profesional o para desenvolver- 
se en un oficio para las mujeres han sido establecidas por la sociedad. En nuestro país se evidencia un aumento significativo de oportunidades equitativas que permiten una estabilidad económica de las mujeres. Sin embargo, en los avances y derechos que favorecen nuestras necesidades, todavía faltan más leyes con estrategias que sean cumplidas y propendan por un proceso más igualitario y acciones concretas frente a la justicia, los derechos y la reparación.

Aunque es un hecho que existen leyes que buscan proteger el derecho al trabajo, con dignidad, con justicia y con equidad, aún en Colombia es necesario que se trabaje mucho en este campo. La Constitución del 1991, en el artículo 43 determina que "la mujer y el hombre tienen iguales derechos y oportunidades. La mujer no podrá ser sometida a ninguna clase de discriminación." (Extraído de do- cumento: Sisma mujer, 2005, p. 55), pero en la práctica estas leyes no se cumplen, pues es evidente como en la vida de las co-investigadoras, ha existido abuso de autoridad y una serie de condicionamientos que no permiten un normal desarrollo de las actividades laborales, porque limita, coarta y reprime al trabajador llevándolo al silencio para no perder la seguridad económica que le permite suplir con sus necesidades básicas.

Como mujeres desde el interés por conseguir mayor producción, hemos obtenido mejor oferta laboral, en el sentido que nos toman como personas aptas y capacitadas para cualquier desempeño, pero estas asignaciones aún no abolen las estigmatizaciones de debilidad. Al respecto manifiesta Lagarde $(1990,5)$ esto, "se debe al poder real y simbólico de los hombres ya que lo más afectado para ellos es su virilidad." Por lo cual,

Figura 3. Silencios efervescentes

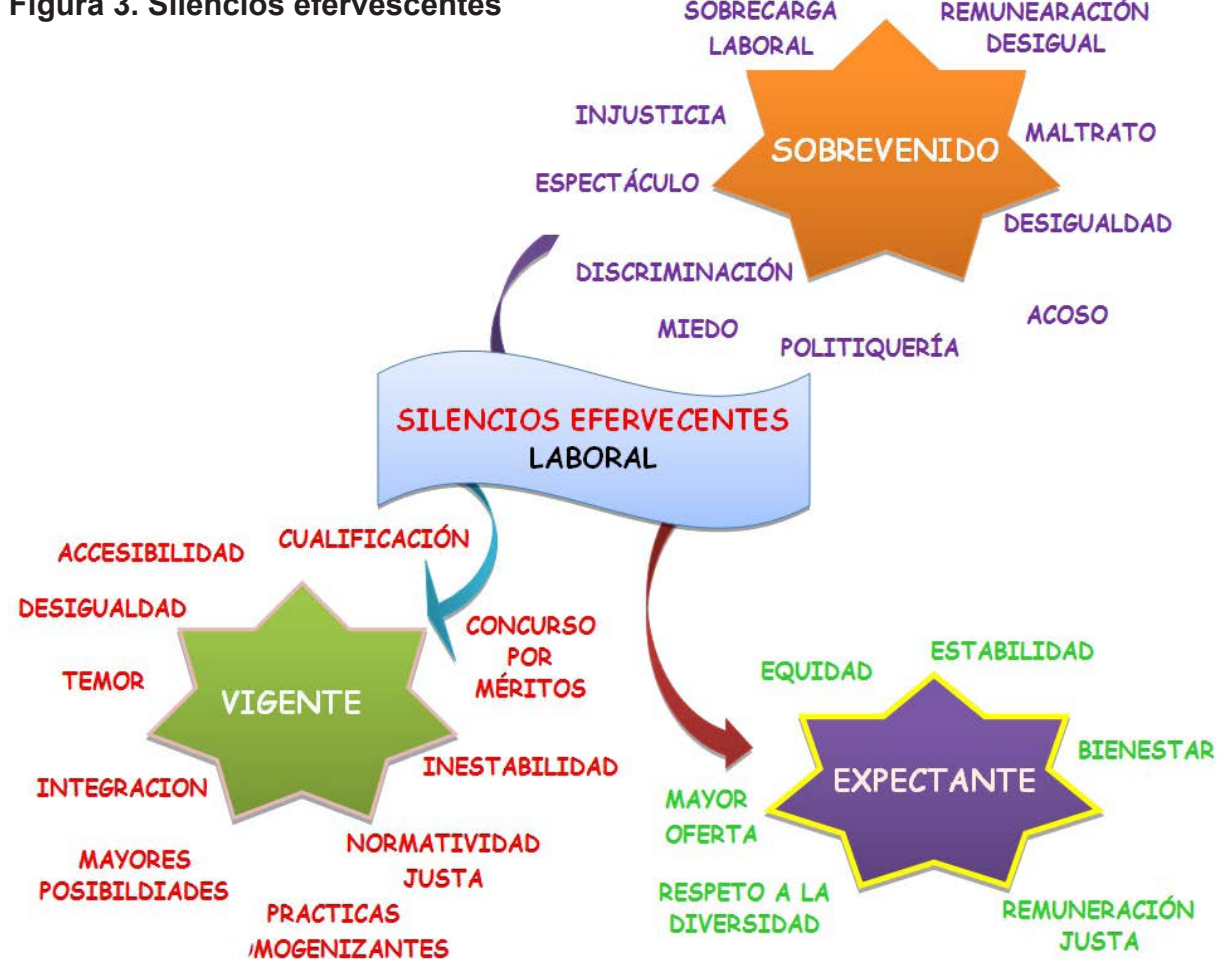

CUALIFICACIÓN 
las remuneraciones económicas y de status aún siguen con un trasfondo machista e inequidad en el proceso de desarrollo de las funciones y retribuciones laborales.

En este sentido, silencios efervescentes presenta una síntesis en tres apartes de los análisis e inferencias que partiendo específicamente de las experiencias laborales que han tenido las co-investigadoras. En el primer aparte sobrevenido encontramos que la remuneración desigual, la sobrecarga laboral, la injusticia, el maltrato, el acoso y la discriminación fueron algunos de factores que evidenciaban como desde tiempo atrás y a pesar de habérsele conferido a la mujeres el derecho a la profesionalización y el trabajo, la mujer no dejo de ser presa de las injusticias por parte de los hombres, las instituciones y la sociedad. El segundo aparte vigente alude a los cambios más significativos que han ocurrido hasta el momento frente a la accesibilidad, la cualificación, el concurso por méritos, algunas normatividades justas y mayores posibilidades laborales, que son de gran valor pero en los cuales aún hoy en día se sigue manteniendo el temor, la desigualdad, la inestabilidad y las prácticas homogenizantes que desconocen la inclusión y la diversidad que hacen parte de las capacidades intelectuales, físicas, de edad y sexo que deben ser tenidas en cuenta para la realización de ciertas labores. El tercer aparte referente a lo expectante sugiere unos posibles factores que deducimos pueden ser pioneros no sólo de mejorar los contextos laborales sino de abolir totalmente las prácticas y condiciones segregadoras como por ejemplo que sea un hecho y práctica la equidad, las mayores ofertas, la estabilidad, el respeto a la diversidad, la remuneración justa y el bienestar, y no que sean quimeras irrealizables de decretos que quedan escritos en la normatividad o las leyes sin posibilidades de realización debido a la gobernación jerárquica y los sistemas capitalistas.

\section{El eco de los silencios}

Las conclusiones derivan de la pregunta que nos movilizó, los objetivos planteados y el análisis de los resultados a los que se llegó mediante el estudio de las didactobiografías de las co-investigadoras y el aporte de los teóricos.

$>$ Como primer paso se identificó cuáles son los silencios personales y cómo éstos en nuestra labor docente tienen implicaciones con efectos dañinos en el ejercicio académico y formativo de los estudiantes; Fromm (1993, p. 278), nos dice "la educación conduce con demasiada frecuencia a la eliminación de la espontaneidad y a la sustitución de los actos psíquicos originales por emociones, pensamientos y deseos impuestos desde afuera". Por tanto, estos patrones de educación recibida replicamos erróneamente, considerando que el silencio como método de control, de disciplina y lo que es peor formativo, favorece el desarrollo integral del ser. Sin darnos cuenta que impartimos una metodología de sometimiento, de negación de la libertad, del espíritu de exploración, curiosidad, imaginación y creación inherente en los estudiantes.

> Al descubrir los silencios referentes a los roles como hijas, hermanas, madres, amantes, mujeres y docentes, inferimos que éstos vienen marcados y maniobrados por un ciclo frecuente de dominio, que Foucault llamo "ciclos de repetición", que determinados y obligatoriamente empezamos a adquirir con el tiempo, con la formación y ambiciones que nos constituyen.

$>\quad$ La interpretación a las didactobiografías como "historia que se objetiva en una narración que da cuenta del desafío de leer y sistematizar el conocimiento de la realidad, a partir del análisis del presente en perspectiva histórica" (Quintar, 2013, 13), llevo a entender que los silencios son un medio de control de los sistemas de 
gobierno, modelos familiares, culturales, políticos, económicos, religiosos y sociales que nos han regido en todas las épocas. Así, el silencio es una vía en que la autoridad y la jerarquía se manifiesta para limitar, reprimir, causar miedo y temor según el grado de poder que represente.

$>$ En el contexto educativo, se reconoce que los silencios más frecuentes de las docentes en el aula de clase, son los representativos a las imposiciones de poder y de disciplina "castigos disciplinarios" Foucault (1984). Sus narraciones evidencian que recibieron una educación disciplinaria y del castigo, y, ésta inconscientemente vuelve a replicarse. Por ejemplo: las normatividades y reglamentos que contempla los manuales de convivencia se reflejan en el aula de clase en forma de autoridad que de forma sutil sanciona, prohíbe, señala, exige y presiona para lograr el orden, el control y resultados satisfactorios por los que debe responder el docente.

$>$ Los silencios encontrados se clasificaron desde dos ópticas. La primera, hay silencios que provienen del ámbito del poder y de los lenguajes del poder, como mecanismos de disciplina que coartan la libre expresión, tienen un efecto que conlleva a la sumisión y conformismo del individuo a lo que se le implanta como norma, verdad o ley. Y la segunda, hay silencios que provienen de las necesidades de intimidad y privacidad, como proceso introspectivo y evaluativo del individuo, como espacio de análisis, reflexión y cuestionamiento del rol que asume y cumple el individuo en la sociedad.

$>$ Asimismo, analizamos que silenciamos principalmente los miedos, las inseguridades, el desconocimiento, las aspiraciones, el amor, los sueños, el conocimiento previo que poseemos y aquella autonomía o libertad que tanto se promulga como el ideal de formación para la dignidad humana.
Estos son los silencios que en muchos casos desde temprana edad la familia, los adultos o quienes están a cargo de nosotros -dado el caso las y los docentes- empiezan a implantarnos como patrones de conducta, obediencia y comportamiento que se direcciona según el grado de poder que tengan o tengamos directamente sobre otros.

$>$ Los hallazgos encontrados nos permitió entender que los silencios tienen implicaciones, las cuales se ven reflejadas en el presente como construcción histórica que nos constituye como sujetos. A lo que Guarín refiere, "la modernidad es también una crítica de sí misma, de sus fundamentos, de sus ideales, de sus unidades, dialécticas, de sus principios, leyes, verdaderas, supuestos, métodos y fines. La modernidad es autocritica". Es decir, las épocas de sentido son autocríticas se interesan por el pasado, por sus memorias y su historia en relación a los acontecimientos del presente que identifican a una colectividad.

\section{Tonalidades recomendadas}

En las recomendaciones que a continuación exponemos se propone abrir camino a nuevas investigaciones interesadas en contribuir a las necesidades y propósitos de la educación donde confluyen el poder y los lenguajes de poder con sus consecuencias sobre el sujeto y la sociedad que le pertenece.

$>$ Teniendo en cuenta cómo operan los mecanismos del poder, es necesario ahondar en las prácticas del silencio disciplinario, inmersas en la educación, pues "se puede hablar en tal sentido de una escuela del miedo, la amenaza, la doctrina, el castigo" (Guarín, 2009, 264), que reprime la voz, la opinión, los intereses particulares de las y los estudiantes y desencadenan en ellos actitudes de 
inseguridad tanto para hablar como para actuar, temor a quedar en ridículo, prácticas pragmáticas que en la edad adulta se convierten en actitudes autoritarias que llevan a que se pierda los procesos comunicativos sanos y colectivos.

> "Silencios de las mujeres docentes" invita a la búsqueda de nuevas prácticas sociales de la inclusión, del respeto a la diversidad tanto de género como de raza y al reconocimiento de los grupos vulnerables que han silenciado las injusticias, las guerras, las violencias, los odios y la indiferencia de quienes podemos intervenir para mejorar sus condiciones de vida. González (2011, p. 5), nos dice "La provocación es reincidente, es en nosotros donde reside la posibilidad de seguir pensando la alteridad, la diversidad, de seguir pensando qué es eso de extrañar al otro, cómo podemos nombrar lo otro que venimos silenciando." Pues escuchar y reconocer a los otros en la socialización, propicia espacios más humanizantes e integradores de las colectividades y su diversidad.

> Se recomienda, repensar la escuela y las prácticas de aula que perpetuán el poder del dominio, del sometimiento y la vigilancia. Abordando las situaciones desde otra perspectiva que re-direccione convenciones sociales, políticas, religiosas, económicas y culturales provenientes de las imposiciones bancarias, mercantiles y de consumo que impiden la realización autónoma y colectiva de las personas.

$>$ Se sugiere reconfigurar el ejercicio académico, donde se tenga en cuenta que el silencio no debe aplicarse como un poder o autoridad frente a los estudiantes. Pues para construir en colectivo es necesario escuchar al otro, en palabras de Lenkersdorf, (2008, p. 31) sería "El escuchar a fondo percibe realidades para nosotros escondidas". Es darle importancia a su voz, es devolverle la palabra y evitar mutismo selectivo y/o coercitivo.

$>$ Se hace necesario que emerjan nuevas visiones y estrategias metodológicas de aula, en las que el silencio sea usado como medio para la interiorización, el encuentro de potencialidades y posibilidades que bien vale la pena rescatar en pro de ofrecernos la oportunidad y espacios para expresarnos, donde "entender, o hacerse entender, es un proceso de comunicación entre sujetos que comprenden no sólo un sistema de signos, sino que entienden 'el juego del lenguaje' que se usa en un contexto dado" (Vattimo, 1986, p. 13). Otros lenguajes de existencia y creación que conducen a artesanar y recuperar la confianza, los saberes, la identidad, la memoria y la cultura que representamos como bien común en la trasformación y constitución de nuevas perspectivas de humanidad.

$>$ Es necesario hablar con la verdad que nos pertenece como actores de cambio responsables de la formación de las presentes y futuras generaciones. Pues, "Porque estamos en el mundo, porque nos vemos afectados por las situaciones, y porque nos orientamos comprensivamente en esas situaciones, tenemos algo que decir, tenemos experiencia que traer al lenguaje" (Ricoeur, 2011, 34). Historia y presente de sentido con experiencias de vida que deben proyectarse a acabar con aquellos silencios de dominio y opresión, y a cambio, promover el reconocimiento del lenguaje con didácticas de recuperación del tejido social. 


\section{Bibliografía}

\section{Fuentes}

Álzate, Margarita. Guzmán, Fredy. Henríquez Hubert y Meléndez Elsi. (2011). Los olvidos de los docentes. Universidad de Manizales. Manizales, Colombia.

Ávila-Fuenmayor, Francisco (2007). El concepto de poder en Michael Foucault. Revista de Filosofía, A Parte Reí 53.

Beauvoir, Simone de. (2009). El existencialismo y la sabiduría de los pueblos. Gallimard. ed (en español). 1 edición. Barcelona, España: Edhasa.

Beauvoir, Simone de. (1949). El segundo sexo. Buenos Aires: Siglo Veinte.

Botero, Patricia. (2011). La construcción del conocimiento social. Maestría en Educación desde la diversidad .CEDUM: Universidad de Manizales.

Carnero, Silvia. (2005). La condición femenina desde el pensamiento de Simone de Beauvoir. Revista APARTE REÍ 40, Julio de 2005.

Collazos Osorio, Clara y González Rouillé, Luisa María. (2012). Lenguajes del poder. Miedos de los docentes. Revista Plumilla Educativa No 10, pp. 238-253. Manizales: Universidad de Manizales.

Delgado, Juan Manuel y Gutiérrez, Juan (1995). Métodos y técnicas cualitativas de investigación en ciencias sociales. Editorial Síntesis S.A. Madrid.

Demouse, Loyd (1982). Historia de la Infancia. Volumen 321. Editorial Alianza, Universidad Nueva York.

Foucault, Michel. (1999). Estrategias de Poder. Edición Paidos, España. Pp, 41-55.

Foucault, Michel. (1984) Vigilar y Castigar, nacimiento de la prisión. Traducción, Aurelio Garzón del camino. Editorial, XXI Siglo Veintiuno Editores. $9^{\mathrm{a}}$. Edición, nueva criminología.

Foucault, Michel. (1968) Las palabras y las Cosas, una arqueología de las ciencias humanas. Siglo XXI Editores, S.A. de C.V.

Frank, Ana. (2005). El diario de Ana Frank, testimonio. Editorial SKLA, Bogotá, D.C. Colombia.

Fromm, Erich. (2000). El arte de amar. Traducción al español por Noeni Rosenblatt.
Ediciones Paidos Ibérica. Ciudad de México, México.

Fromm, Erich. (1993). El Miedo a la libertad. Versión castellana de Gino Germani. Director del Instituto de Sociología de la Universidad de Buenos Aires. Buenos Aires. Editorial Paidos.

Galeano M. María Eumelia. (2004). Diseño de proyectos en la Investigación cualitativa. Fondo editorial universidad Eafit. Medellín.

Garcés, Marina (2005). La vida como concepto político: Una lectura de Foucault y Deleuze. Universidad de Zaragoza. Athenea Digitalnúmero. 7:78- 40.

Gianni Vattimo. (1986). El fin de la modernidad. Ed. Gedisa, Barcelona.

González González, Miguel Alberto. (2012). Falacias de la igualdad y precariedades de la libertad. Manizales: Universidad de Manizales.

González González, Miguel Alberto. (2011). El extrañamiento del otro. Manizales: Universidad de Manizales.

González González, Miguel Alberto. (2009). Horizontes humanos: límites y paisajes. Capítulo V: ¿Qué significa pensar para la literatura y para la filosofía? y EI lenguaje como generador de Conflictos. Manizales: Universidad de Manizales, Colombia.

Guarín Jurado, Germán. (2011). Modernidad Positiva. Modernidad Crítica. Módulo Modernidad crítica: fundamentos epistémicometodológicos. Manizales, Colombia: Universidad de Manizales.

Guarín Jurado, Germán (2009). Hacia una didáctica formativa. Revista Plumilla Educativa No 6, pp. 261-268. Manizales: Universidad de Manizales.

Guarín Jurado, Germán. (2004). Razones para la racionalidad en horizonte de complejidad. Manizales, Colombia: Universidad de Manizales.

Kafka, Franz. (1919). Carta a su padre. Editado por elaleph.com. (C) 2000 - Copyright www. elaleph.com

Lenkersdorf, Carlos. (2008). Aprender a escuchar. Enseñanzas maya-tojolabales. Plaza y Valdés, Editores. 
Lezcano Pajón, Yolima (2012). El reflejo profundo de mis silencios. Investigación: Silencios de las mujeres docentes. Estudiante de Maestría en Educación desde La Diversidad. Universidad de Manizales, Caldas- Colombia.

López Daza, Diva (2012). Viaje autobiográfico por mis silencios. Investigación: Silencios de las mujeres docentes. Estudiante de Maestría en Educación desde La Diversidad. Universidad de Manizales, Caldas- Colombia.

Mistral, Gabriela. (1924). Lecturas para mujeres, destinadas a la enseñanza del lenguaje. Secretaría de Educación de México, Departamento Editorial, México.

Noelle-Neumann, Elisabeth. (1992). La espiral del silencio. Opinión pública: nuestra piel social. Traducción de Javier Ruíz Calderón. Versión limitada de la original de 1984. Paidos. Barcelona

Reyes Campo, Luz Dey (2012). Carcajada de una vida silenciosa. Investigación: Silencios de las mujeres docentes. Estudiante de Maestría en Educación desde La Diversidad. Universidad de Manizales, CaldasColombia.

Ricoeur, Paul. (2011). Teoría de la interpretación. Discurso y excedente de sentido. Traducción de Graciela Monges Nicolau, de la primera edición en inglés de 1976. Editorial, XXI Siglo Veintiuno.

Rodríguez Caicedo, Ángela María (2012). Un trozo de mí vida. Investigación: Silencios de las mujeres docentes. Estudiante de Maestría en Educación desde La Diversidad. Universidad de Manizales, Caldas- Colombia.

Sigmund, Freud. (2013). Sigmund Freud. Cartas a sus hijos. Traducción Florencia Martín y Alejandra Obermeier. Colección Testimonios. Barcelona: Ediciones Paidós.

Tobón Franco Rogelio. (1987). Semiótica del silencio. Primer premio -Área científicaConcurso de obras inéditas de carácter Literario y Científico. Serie autores de hoy, Concejo de Medellín.

Von Der Walde Uribe, Giselle. (2001). Filosofía y silencio, formas de expresión en el Platón de la madurez. Editorial Pontificia Javeriana.
Gómez-Heras. José $M^{a}$. ( $S$, f.). La Hermenéutica de la Vida en Dilthey y La Fundamentación de una "Crítica de la Razón Histórica" Universidad de Córdoba. En: institucional.us.es/revistas/themata/01/05\%20 Gomez\%20Heras.pdf (Recuperado en marzo 01 de 2012).

Guarín Jurado, Germán. (2010). Biografía del conocimiento. En: http://es.scribd.com/ doc/31322523/Biografia-Del-ConocimientoGerman-Guarin (Recuperado en febrero 16 de 2013).

Lagarde y de los Ríos, Marcela. (2008). Amor y sexualidad, una mirada feminista. Curso de Verano Universidad Menéndez Pelayo. En: www.bduimp.es/archivo/.../ pdf/08_10193_17_Lagarde_idc37747.pd... (Recuperado êl 7 de febrero de 2013).

Lagarde y de los Ríos, Marcela. (1990). Identidad femenina. En: webs.uvigo.es/xenero/ profesorado/purificacion.../identidad.pdf (Recuperado el 7 de febrero de 2013).

Mistral, Gabriela. (S, f.). Poemas. En www. google.com/centrovirtualcervantes (Recuperado febrero 17 de 2013).

Ottonello, Rodrigo. (2011). Michel Foucault: más allá del silencio y la soberanía. En: www.fflch.usp.br/dcp/leviathan/index.php/ leviathan/article/.../pdf_19!. (Recuperado el 20 de julio 2013).

Sisma Mujer. (2005). La violencia contra las mujeres en Colombia: ¿Se hará justicia? Proyecto ley integral de violencia contra la mujer. Corporación Sisma Mujer. Bogotá, Colombia. Disponible en:www.sismamujer. org/las-violencias-contra-las-mujeres-encolombia- ¿se- (Recuperado marzo $11 \mathrm{de}$ 2013).

Vázquez García, Verónica. y Chávez Arellano, María Eugenia. (2008). Género, sexualidad y poder. El chisme en la vida estudiantil de la universidad Autónoma Chapingo, México. Estudio sobre las culturas contemporáneas, junio/vol. XIV; número 027. Universidad de Colima. Colima - México. pp. 77-112. En: http://redalyc.uaemex.mx/ pdf/316/31602704.pdf (Recuperado el 01 de febrero de 2013). 


\section{Referencias}

(Recuperado el 21 de abril de 2012). Bogotá, Colombia.

Ávila-Fuenmayor, Francisco (2008). La complejidad del saber-poder: hacia la emancipación de Latinoamérica. Revista de Estudios Interdisciplinarios en Ciencias Sociales. Universidad Rafael Belloso Chacín. ISSN 1317-0570 Depósito legal pp: $199702 Z U 3$. Vol. 10 (2): 290-307.

Definición de silencio - Qué es, Significado y Concepto. (S, f.). En: definicion.de/silencio/ (Recuperado en mayo 20 de 2012).

Diccionario de la lengua española. (S, f.). En: http://www.rae.es/rae.html (Recuperado en marzo 11 de 2012).

Garrido, Miguel Armando (2008).El valor del silencio, en el proceso de mediación. Un medio para la paz. En: www.monografias. com/...pdf/silencio.../silencio-mediacionpaz-proc... (Recuperado mayo 20 2012).

González González, Miguel Alberto. (2010). Umbrales de indolencia. Educación sombría y justicia indiferente. Manizales: Universidad de Manizales.

González González, Miguel Alberto. (2012). Horizontear las utopías y las distopías. Tensiones entre lo apolíneo y lo dionisiaco. Madrid: Editorial académica española. http://www.bbc.co.uk/mundo/noticias/2012/06/120608_aniversario_hui- da carcel alcatraz cinco claves vp.shtml (Recuperado el 12 de junio de 2012).

Londoño C. Viviana. (2012). El lenguaje de las tumbas. Cómo entender el valor del epitafio como un género corto. El espectador. En: www.elespectador.com/impreso/.../articulo340259-el-lenguaje-de-tumb..."

Massuh, Victor. (1985). Nietzsche y el fin de la religión. Primera edición septiembre de 1969 y tercera edición junio de 1985. Editorial Sudamericana.

Mistral, Gabriela. (S, f.). Vida y obras. En www. google.com/centrovirtualcervantes (Recuperado en febrero 13 de 2013).

Perasso, Valeria. (2012). Alcatraz: cinco claves para entender la historia de una 'cárcel maldita'. BBC Mundo, California. En:

Quintar, Estela. (2013) Entrevista a Estela Quintar. Revista Pedagógica de la Universidad de Lasalle. Bogotá, Colombia. En: www.ipecal.edu.mx/Biblioteca/Documentos/ Documento2.pdff' (Recuperado el 11 de febrero de 2013).

Sigmund, Freud. (1893-1895). Obras completas de Sigmund Freud. Volumen II - Estudios sobre la histeria. Traducción José Luis Echeverry. Buenos Aires \& Madrid: Amorrortu Editores.

Zambrano, María. (2011). Filosofía y Educación (Manuscritos). Edición de Ángel Casado y Juana Sánchez-Gey. Editorial Club Universitario, España. 